Research Article

\title{
Bibliometric and Content Analysis of Research Trends on the Use of Serious Games to Assist People with Disabilities
}

\author{
Nuri KARA *1 (D) \\ ${ }^{1}$ Istanbul Bilgi University, Turkey, nuri.kara@bilgi.edu.tr
}

*Corresponding Author: nuri.kara@bilgi.edu.tr

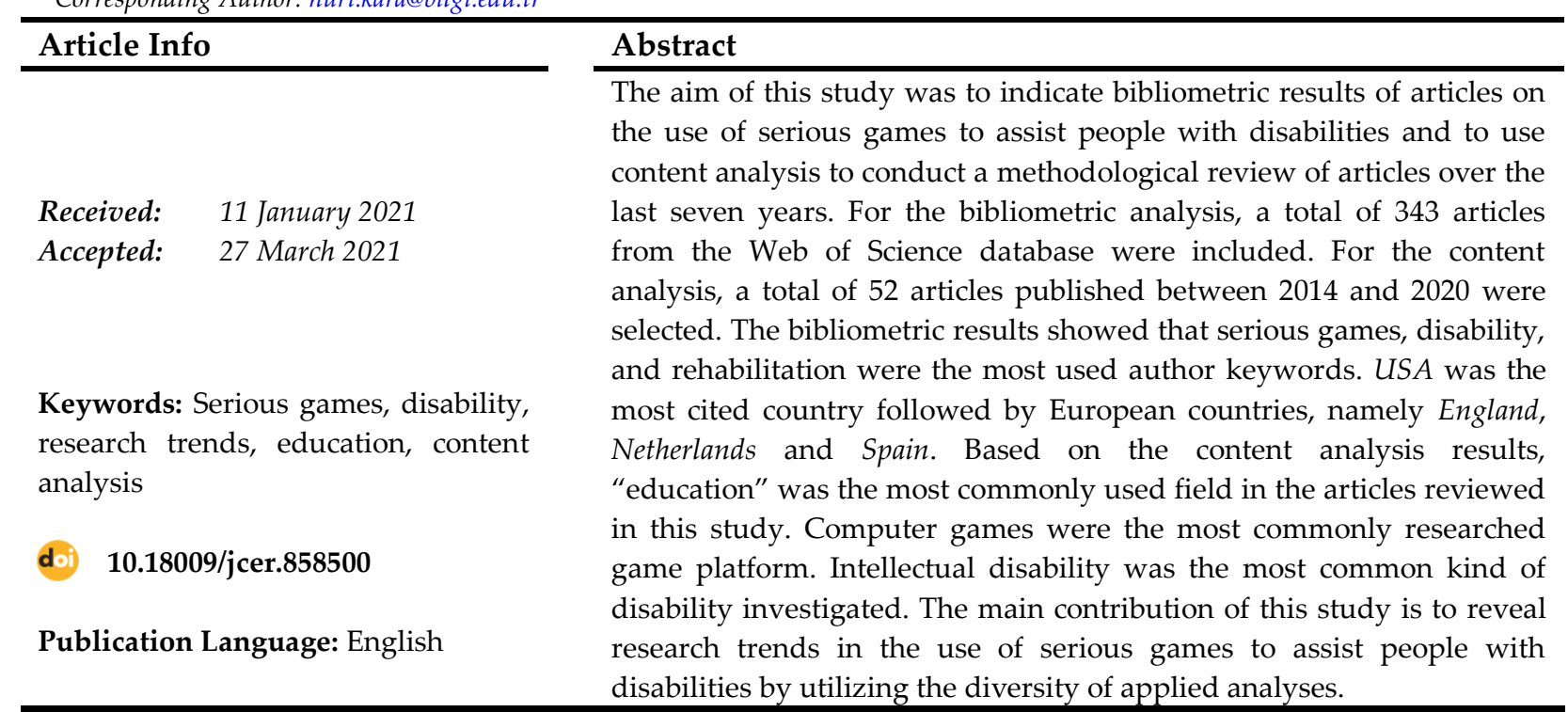

open access (a) CrossMark Cc)

To cite this article: Kara, N. (2021). Bibliometric and content analysis of research trends on the use of serious games to assist people with disabilities. Journal of Computer and Education Research, 9 (17), 278-299. DOI: $10.18009 /$ jcer. 858500

\section{Introduction}

The use of serious games (SG) has increased in recent years. Serious games are defined as games used for purposes other than entertainment, enjoyment, or fun (Michael \& Chen, 2006; Susi, Johannesson, \& Backlund, 2007). Serious games have been used in a variety of application areas: military, education, government, health, corporate, among others (Connolly, Boyle, Hainey, McArthur, \& Boyle, 2012; Susi et al., 2007). Health and wellbeing is one of the major fields for which serious games have been developed and used. Systematic literature reviews show the effectiveness of game-based approaches for health and wellbeing (Chow et al., 2020). Disability, which can be related to health and wellbeing, is also a prominent area in which serious games have been integrated. The term disability is used here as a general term to indicate impairments, activity limitations, and participation 
restrictions (World Health Organization, 2011). Since the beginning of the 2000s, numerous research studies have indicated positive impacts and outcomes of playing games (Boyle et al., 2016). Recent research shows that video games are increasingly developed for people with different disabilities such as autism spectrum disorders, intellectual disabilities, and learning disabilities. These games are also used in special education to support individuals' wellbeing and the development of their social skills (Durkin, Boyle, Hunter, \& ContiRamsden, 2013; Terras, Boyle, Ramsay, \& Jarrett, 2018).

There have been several review studies analyzing the use of serious games for disabled people. Tang, Chen, Falkmer, Bölte, and Girdler (2019) conducted a systematic review and meta-analysis of social-emotional computer-based interventions for autistic individuals using the serious game framework. The aim of the study was to review the application of serious game principles in social-emotional computer-based interventions targeting autistic individuals and evaluate the effect of these principles in remediating socialemotional outcomes via meta-analysis. Tsikinas and Xinogalos (2019) examined the available literature on the effects of serious games on people with intellectual disabilities or on people on the autism spectrum in line with the systematic literature review. Proença, Quaresma, and Vieira (2018) carried out a systematic review of the use of gaming platforms with serious games in the upper limb rehabilitation of patients with neuromotor disorders. Bonnechere et al. (2014) conducted a systematic review of the use of serious games in rehabilitation with conventional treatment of children with cerebral palsy. Looking at these review studies, two commonalities become apparent. First, each of these reviews focused on a specific disability type. Second, serious games were examined in the context of disability studies. As seen in the review studies, methodological research trends and common gaming platforms or disability types have not been covered in detail. Hence, this study focuses on the research trends in the use of serious games to assist people with disabilities. Besides, this study incorporates the diversity of applied analyses instead of a single analysis method which has been included in the majority of the previous studies.

The research questions of this study are:

1. What are the most used author keywords in articles on the use of serious games to assist people with disabilities? 
2. Who are the most cited authors in articles on the use of serious games to assist people with disabilities?

3. What are the most cited countries in articles on the use of serious games to assist people with disabilities?

4. What were the dominant fields of articles on the use of serious games to assist people with disabilities?

5. What were the research methods applied in articles on the use of serious games to assist people with disabilities?

6. What were the data collection tools included in articles on the use of serious games to assist people with disabilities?

7. What were the most preferred sampling groups and sample sizes in articles on the use of serious games to assist people with disabilities?

8. What were the data analysis methods covered in articles on the use of serious games to assist people with disabilities?

9. Which game platforms were studied in articles on the use of serious games to assist people with disabilities?

10. What were the disability types examined in articles on use of serious games to assist people with disabilities?

\section{Method}

\section{Literature review and exclusion criteria}

This study aims to indicate research trends on the use of serious games to assist people with disabilities by using bibliometric and content analysis. For the bibliometric analysis, SSCI, SCI-Expanded, A\&HCI, CPCI-S, CPCI-SSH, and ESCI indexes listed in the Web of Science database were selected to gather the maximum number of articles. The timespan of "all years" was used to include articles published from 1975 to 2020 (access date: December 2020). Since the terms serious games, digital games, and educational games are used interchangbly in many articles, the following keywords were entered in the topic section of the database search: "serious game" OR "digital game" OR "educational game". As well, to include disability-related articles, "disability" OR "special education" were used 
as keywords in database searches. A total of 343 articles were located. All articles were exported with full records and cited references in tab delimited (Win) file format.

For the content analysis, specific review steps which were explained in Arici, Yildirim, Caliklar, and Yilmaz's (2019) study were implemented. Selecting indexes, determining keywords as topics, choosing the language, arranging the time span and applying the inclusion or exclusion criteria were the main steps for listing the articles to be included in the content analysis (Arici et al., 2019). Based on this guideline, SSCI, SCIExpanded, and A\&HCI indexes listed in the Web of Science database were selected as the literature source. These indexes were chosen because of their prominent status in indexing core and high-ranking journals (Cheng, Chen, Chu, \& Chen, 2015). The keywords "serious games" and "disability" were entered in the topic section. The searches were further refined by limiting results to English-language articles and to the timespan 2014-2020. There were two reasons for using this timespan. The first was to focus on the most recent trends in research in this area. The second was related to the increasing number of articles appearing after 2014 based on the bibliometric results. The first search produced a total of 84 published articles related to serious games and disability. All 84 articles were reviewed, and specific exclusion criteria were implemented to finalize the articles (see Table 1).

Table 1. Exclusion criteria for the content analysis

- Articles where only the abstract is available rather than the full text

- Articles referring to a serious game but which are not directly related to disability

- Articles listed in Web of Science database but not indexed in SSCI, SCI-Expanded, or A\&HCI indexes

Finally, a total of 52 articles were selected for content analysis in this study. The article selection procedure is visually explained in Figure 1. 


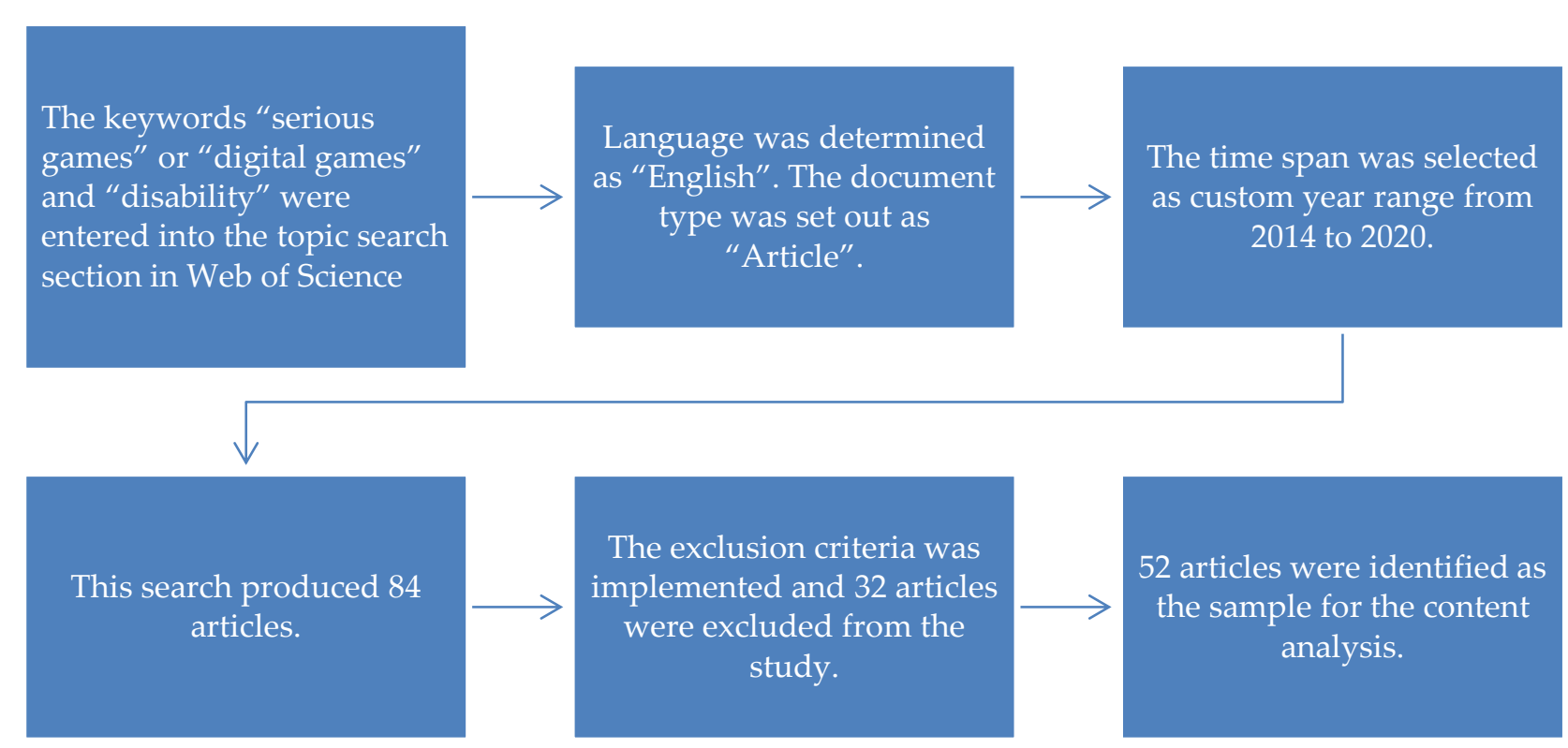

Figure 1. Article selection procedure for the content analysis

Data collection and analysis

For bibliometric analysis, VOSviewer was used to reveal the network maps of the author keywords and citation and co-citation analysis of authors and countries. For the content analysis, a total of 52 articles were reviewed and fully read by the author. All information related to the reviewed articles was inputted into SPSS Statistics 26. Goktas et al.'s (2012) Publication Classification Form was used to analyze the selected articles. Since this form was in Turkish originally, the English version, which was used in Arici et al.'s (2019) study, was used in the current study. The permission of using the classification form in this study was granted. The form includes five parts: (1) title of the article, title of the journal, and author(s) names, (2) research methods, (3) data collection tools, (4) sample groups and sizes, and (5) data analysis methods. Since this study is about serious games and disability, similar review studies were investigated to see whether new sections can be added to the form. Based on this investigation, the dominant field of the study and game categories sections, which were covered in Calderón and Ruiz's (2015) study, were added. In the dominant field section, the major field of the reviewed article was entered, while different gaming platforms, such as PC mobile, virtual reality, augmented reality, and so on, were included in the game categories section. Disability type was also added to analyze the different disability types covered in articles. 
Overall, the classification form implemented in this study includes eight parts: (1) title of the article, title of the journal, and author(s) names (2) discipline, (3) research methods, (4) data collection tools, (5) sample groups and sizes, (6) data analysis methods, (7) game categories, and (8) disability types. The article selection and analysis process was conducted by the author, and related information was entered into the SPSS program via the classification form. Two of the author's colleagues in the Faculty of Communication reviewed this process to ensure that all articles were read completely and data stored in the program was accurate with the reviewed articles. The author and reviewers were in full agreement that the data was consistent with the selected articles and targeted analysis methods.

\section{Findings}

Bibliometric analysis findings

The keywords in articles

Co-occurrence analysis was implemented to identify the most used author keywords in VOSviewer. The minimum number of occurrences was determined as five. Based on the networking map, as shown in Figure 2, there are six clusters and serious game $(\mathrm{s})(\mathrm{f}=65)$ is the most used author keyword. When grouped together, games, digital games, educational games, and video games form the set of the next most frequently used author keywords $(\mathrm{f}=37)$. Disability $(\mathrm{f}=19)$, rehabilitation $(\mathrm{f}=14)$, virtual reality $(\mathrm{f}=14)$, and accessibility $(\mathrm{f}=13)$ round out this list of most frequently used author keywords.

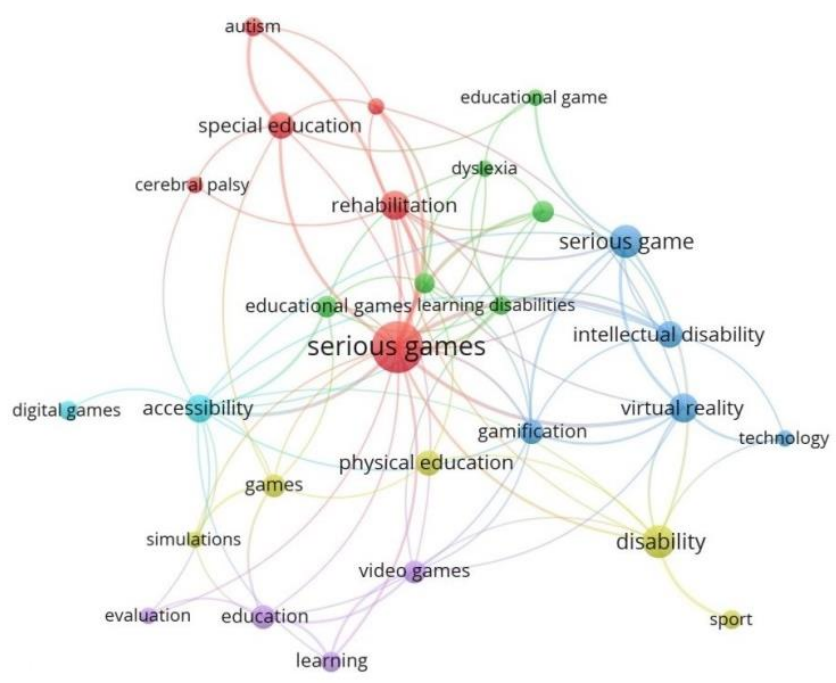

Figure 2. Network map of the most used author keywords in articles 
Based on the network map presented in Figure 3, the number of articles focusing on serious games to assist people with disabilities has increased since 2014. It can also be seen that recent articles focus on "serious game," "gamification," and "digital games."

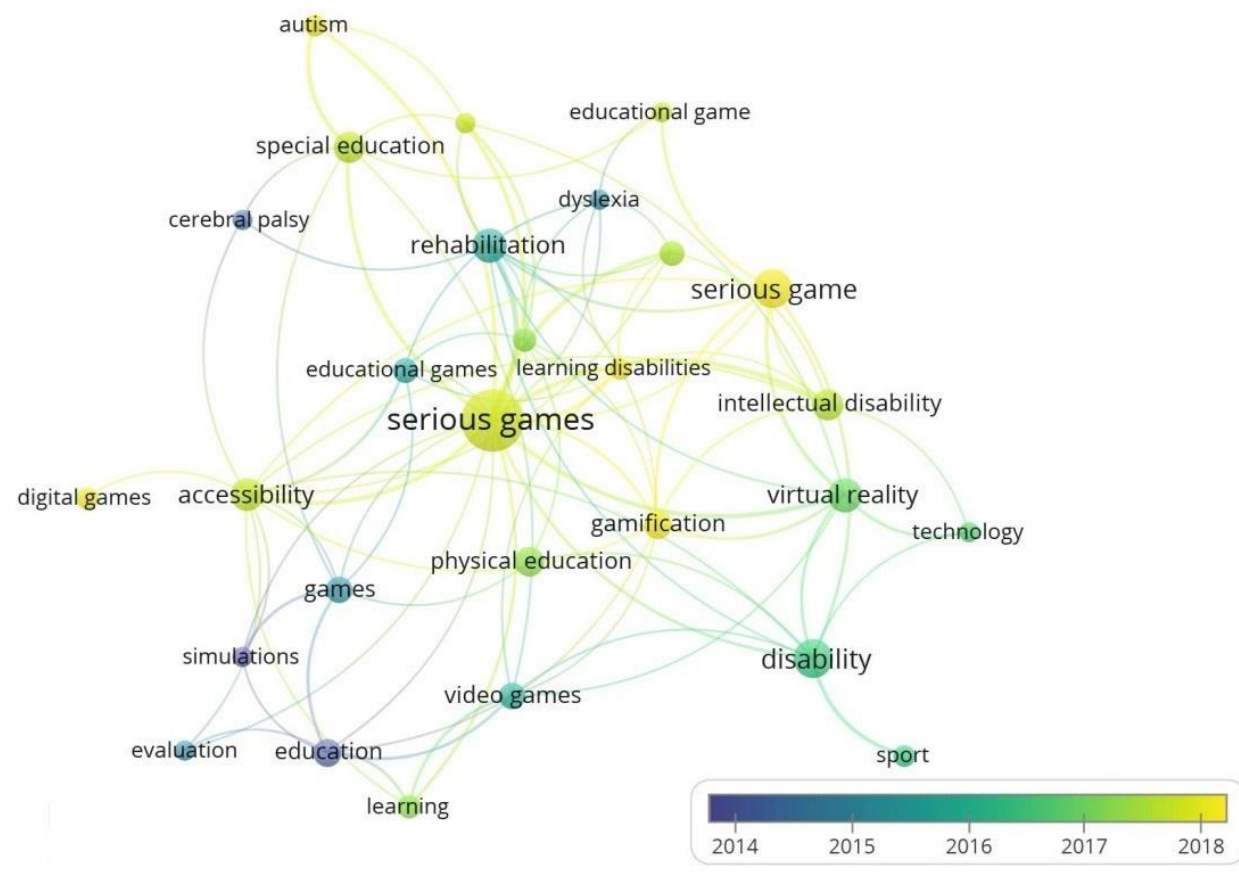

Figure 3. Network map of the most used keywords in articles by year

\section{Most cited authors}

Citation analysis was performed in VOSviewer to indicate the most cited authors. The minimum number of documents of an author was set at three and the minimum number of citations of a source was set at 10. Based on the bibliometric citation findings, five authors were automatically selected by the program. According to the findings, Heikki Lyytinen (69 citations) and Miia Ronimus (69 citations) were the most cited authors (see Figure 4).

Co-citation analysis of authors was also performed in the program. The minimum number of citations of an author was automatically set at 20 and four authors were automatically selected. According to the findings, Gee (26 citations) and Prensky (22 citations) were the most cited authors (see Figure 5). 


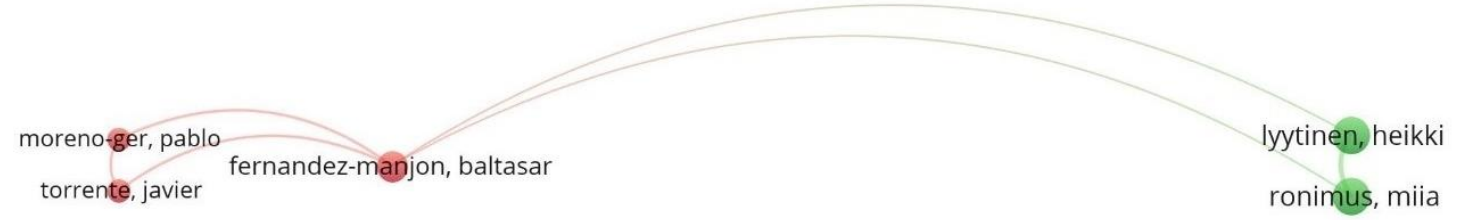

Figure 4. Most cited authors (citation analysis)

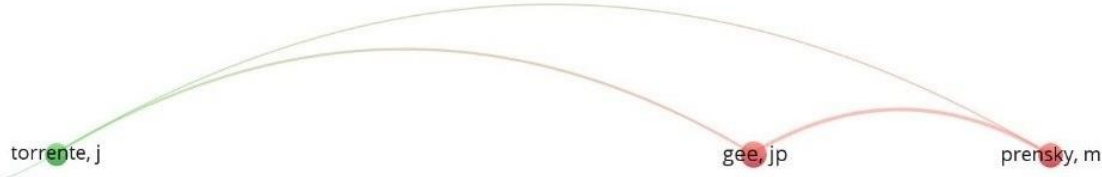

Figure 5. Most cited authors (Co-citation analysis)

Most cited countries

Citation analysis of countries was conducted in VOSviewer. The minimum number of documents of a country and the minimum number of citations of a country were set at ten. The number of countries to be selected was automatically determined as 9. As shown in Figure 6, the USA (1092 citations, 54 documents) is the most cited country followed by European countries, namely England (302 citations, 36 documents), Netherlands (296 citations, 24 documents), and Spain (231 citations, 44 documents).

Based on the network map presented in Figure 7, the USA showed a great citing performance especially in 2014s. However, the citing performances of European countries, such as Spain, England and Netherlands have been increased in recent years.

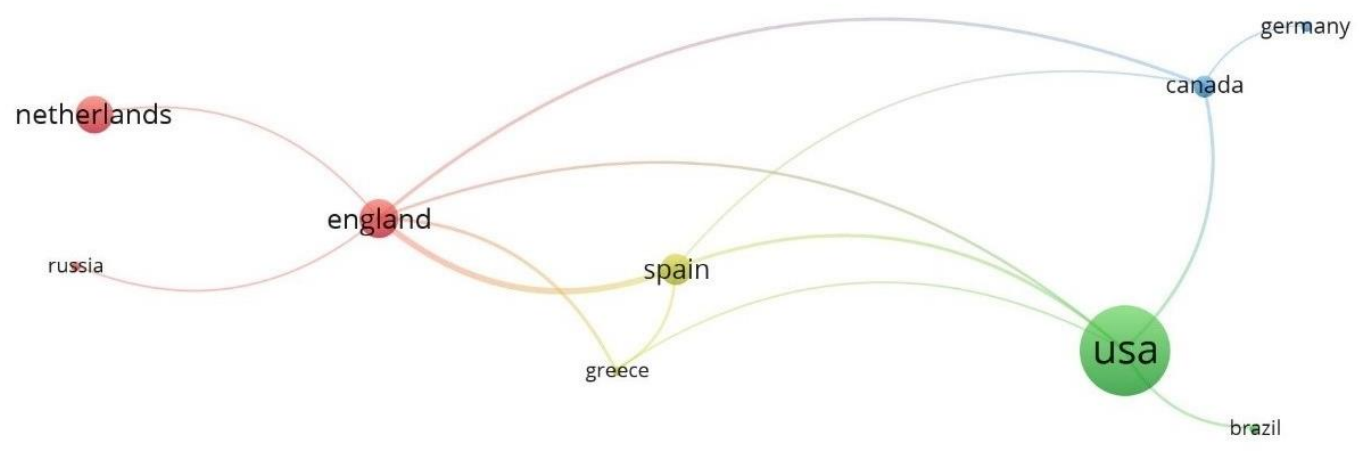

Figure 6. Most cited countries (citation analysis) 


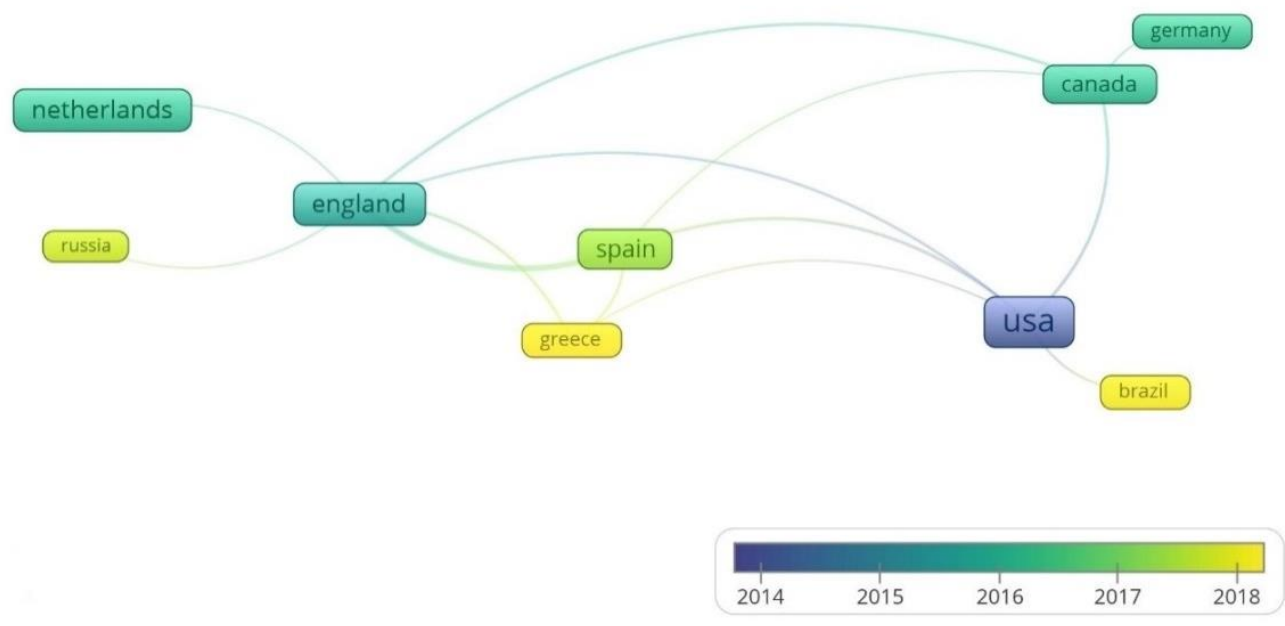

Figure 7. Network map of the most cited countries by year

\section{Content Analysis Findings}

The dominant fields of the studies presented in the articles

Table 2 shows the number of dominant fields of the studies presented in the articles focusing on both serious games and disability. "Dominant" is specified in this category because articles can have more than one field. Hence, the dominant field of each study was determined. Based on the Table 2, education $(\mathrm{f}=22)$ was the most common dominant field in the articles sampled in this study. Rehabilitation $(f=10)$ was the second most emphasized field. Medicine and health, psychology, and engineering/electronics were also examined in many articles, while music and sports were only studied in one article apiece.

Table 2. The frequencies and percentages of the dominant fields

\begin{tabular}{lll}
\hline Dominant Field & Number of Articles & Percentage (\%) \\
\hline Education & 22 & 42.3 \\
Rehabilitation & 10 & 19.2 \\
Medicine and health & 8 & 15.4 \\
Psychology & 5 & 9.6 \\
Engineering / Electronics & 5 & 9.6 \\
Music & 1 & 1.9 \\
Sports & 1 & 1.9 \\
\hline
\end{tabular}

Research Methods

As shown in Figure 8, 55.80\% of the articles studied used quantitative design ( $f=29)$. Review/meta-analysis research was used in $19.20 \%$ of the articles. Qualitative design research was used in $13.50 \%$ of the articles. Mixed design research was used in only $11.50 \%$ of the articles. 


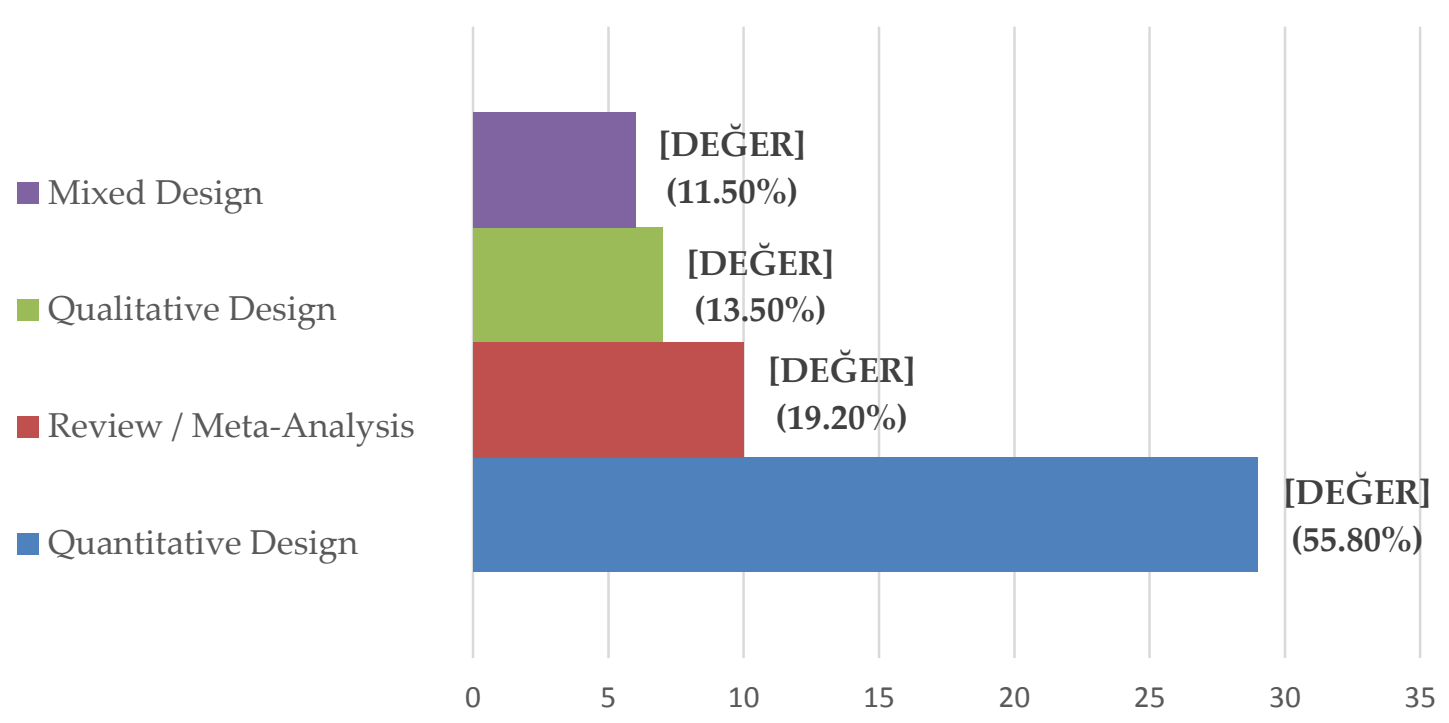

Figure 8. Frequency and percentages of research methods used in the articles

Table 3 summarizes the specific research methods of the articles published between 2014 and 2020. Based on the statistics presented in Table 3, 17.3\% of the articles used descriptive methods as a non-experimental quantitative research design. In experimental design, $15.4 \%$ of the articles included quasi-experimental methods, while $11.5 \%$ of the articles applied true experimental methods. Among the review / meta-analysis studies, literature review was the preferred research method $(11.5 \%)$.

Table 3. Research methods of articles in the use of serious games with disability

\begin{tabular}{lllll}
\hline Research Designs & & Research Methods & f & $\%$ \\
\hline Quantitative & Non-experimental & Descriptive & 9 & 17.3 \\
& Experimental & Quasi-experimental & 8 & 15.4 \\
& & True experimental & 6 & 11.5 \\
& & Pre-experimental & 4 & 7.7 \\
Qualitative & Cross-over experiment & 2 & 3.8 \\
\multirow{2}{*}{ Mixed } & Case study & 5 & 9.6 \\
& & Design research & 2 & 3.8 \\
Review / Meta-analysis & Triangulation & 4 & 7.7 \\
& & Explanatory & 2 & 3.8 \\
& & Literature review & 6 & 11.5 \\
& Meta-analysis & 4 & 7.7 \\
\hline
\end{tabular}

\section{Data Collection Tools}

Figure 9 shows the frequencies of the data collection tools used in articles examining serious games and disability. Based on the statistics, questionnaires ( $\mathrm{f}=26)$, achievement/performance tests $(\mathrm{f}=18)$, and game sessions or interactions of the players $(\mathrm{f}=15)$ 
were the most commonly used tools in the articles. Additionally, interviews or focus group interviews and observations were preferred as data collection tools in nine articles. Compared to these tools, surveys $(\mathrm{f}=6)$ and documents $(\mathrm{f}=6)$ were used less frequently.

Alternative assessment tools

Others

Documents

Surveys

- Observations

Interviews or focus group interviews

Game sessions/interactions

Achievement/performance tests

- Questionnaires

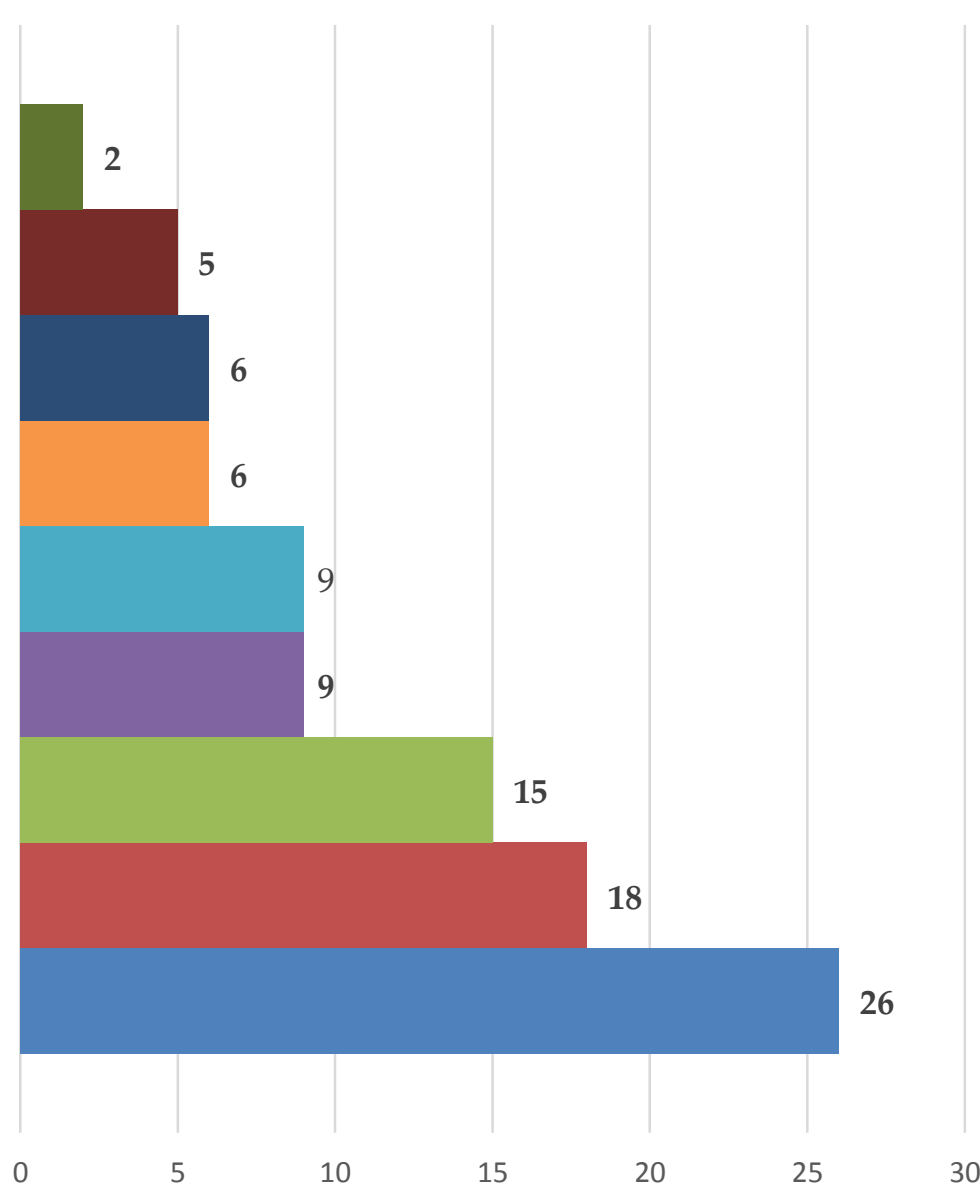

Figure 9. Frequency of the data collection tools

\section{Sampling Groups, and Sample Sizes}

As can be seen in Table 4, adults (42.3\%) were the most commonly used sampling group in articles published between 2014 and 2020. Primary (5-8th grade) students were selected as a sampling group in $15.4 \%$ of the articles, while $9.6 \%$ of the articles used primary (1-4th grade) students. Preschool children (3.8\%), secondary (9-12th grade) students (1.9\%), and teachers $(1.9 \%)$ were the least preferred sampling groups. 
Table 4. Frequency and percentage of sampling groups in articles

\begin{tabular}{lll}
\hline Sampling Groups & f & $\%$ \\
\hline Adults & 22 & 42.3 \\
Primary (5-8th grade) students & 8 & 15.4 \\
Primary (1-4th grade) students & 5 & 9.6 \\
Preschool children & 2 & 3.8 \\
Secondary (9-12th grade) students & 1 & 1.9 \\
Teachers & 1 & 1.9 \\
Not indicated or not applicable & 13 & 25 \\
\hline
\end{tabular}

The findings show that sample sizes of $31-100(25 \%), 11-30(23.1 \%)$, and 1-10 (23.1\%) were most commonly used in the articles examined in this study. The least preferred sample sizes were 101-300 (5.8\%) and 301-1000 (1.9\%) (see Table 5).

Table 5. Frequency and percentage of sample sizes in articles

\begin{tabular}{lll}
\hline Sample Sizes & $\mathrm{f}$ & $\%$ \\
\hline $31-100$ & 13 & 25 \\
$11-30$ & 12 & 23.1 \\
$1-10$ & 12 & 23.1 \\
$101-300$ & 3 & 5.8 \\
$301-1000$ & 1 & 1.9 \\
Not indicated or not applicable & 11 & 21.2 \\
\hline
\end{tabular}

\section{Data analysis methods}

The findings related to data analysis methods of articles show that half or more than half of the articles implemented descriptive analyses, such as frequencies, percentages, and tables $(59.6 \%)$, and means and standard deviations (50\%). Many of the articles also used graphs $(40.4 \%)$ as a descriptive data analysis method. Among the inferential analyses, ANOVA/ANCOVA (21.2\%), non-parametric tests (17.3\%), and T-tests (17.3\%) were the most commonly used data analysis methods. For the qualitative analysis methods, descriptive analysis (17.3\%) was used more than content analysis (11.5\%). Detailed statistics are shown in Table 6. 
Table 6. Data analysis methods in articles researching serious games and disability

\begin{tabular}{llll}
\hline & & $\mathrm{f}$ & $\%$ \\
\hline Descriptive analyses & Frequencies, percentages, tables & 31 & 59.6 \\
& Means, standard deviations & 26 & 50 \\
& Graphs & 21 & 40.4 \\
Inferential analyses & t-tests & 9 & 17.3 \\
& ANOVA/ANCOVA & 11 & 21.2 \\
& Non-parametric tests & 9 & 17.3 \\
& Correlations & 5 & 9.6 \\
& Regression & 4 & 7.7 \\
& MANOVA/MANCOVA & 3 & 5.8 \\
& Factor analysis & 1 & 1.9 \\
& Others & 5 & 9.6 \\
& Content analysis & 6 & 11.5 \\
& Descriptive analysis & 9 & 17.3 \\
& Others & 3 & 5.8 \\
\hline
\end{tabular}

Game Platforms

Figure 10 shows the frequency of game platforms included in articles published between 2014 and 2020. Seventeen articles used computer games as a serious game platform, while nine used mobile games. Other game platforms included motion-sensitive games $(\mathrm{f}=5)$, virtual reality games $(\mathrm{f}=4)$, and augmented reality games $(\mathrm{f}=4)$.

Board game

Virtual worlds

Video game

Augmented reality game

Virtual reality game

Motion sensitive game

Mobile game

- Computer game

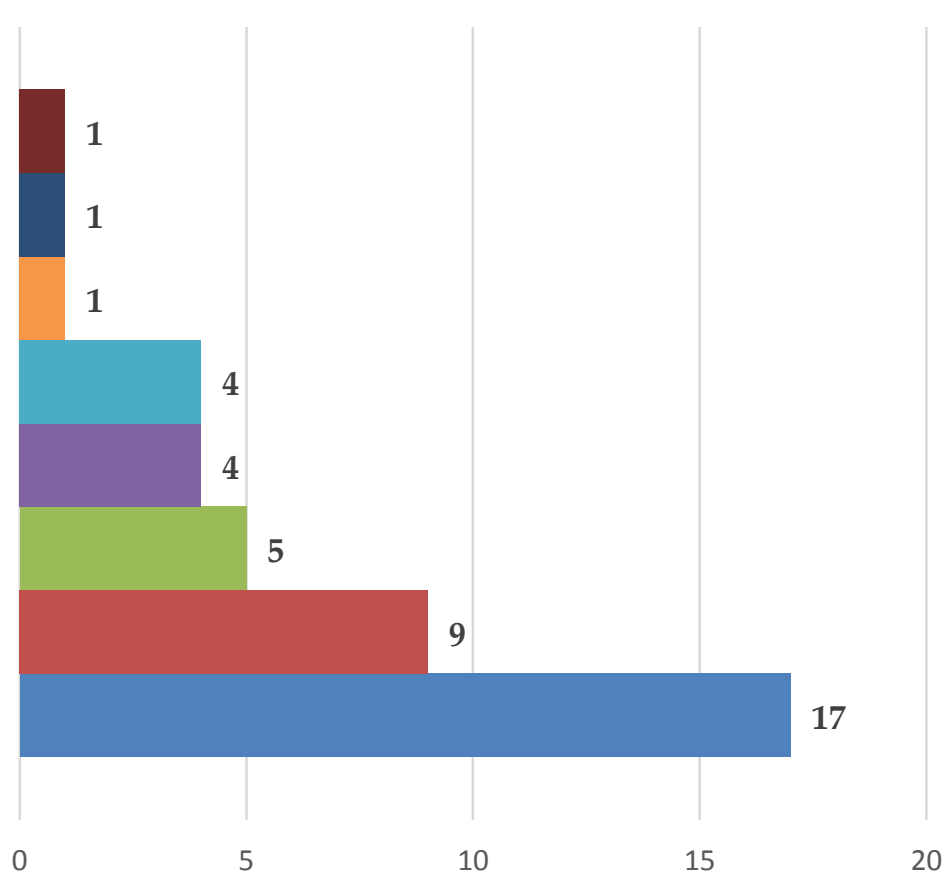

Figure 10. Frequency of game platforms used in articles studying the use of serious games and disability 


\section{Disability Types}

According to the statistics shown in Figure 11, intellectual disability-related studies were published in 14 articles from 2014 to 2020. In addition, 10 articles included developmental disability-related studies in the same time period. Other disabilities included learning disability $(\mathrm{f}=7)$, disability in arm/hand function $(\mathrm{f}=7)$, physical disability $(\mathrm{f}=4)$, reading disability $(\mathrm{f}=3)$, and post-stroke disability $(\mathrm{f}=2)$. Hearing impairment, and visual impairment appeared in one article each.

Hearing impairment
Visual impairment
Post-stroke disability
Reading disability
Physical disability
Disability in arm/hand
function
Learning disability
Developmental disability
Intellectual disability
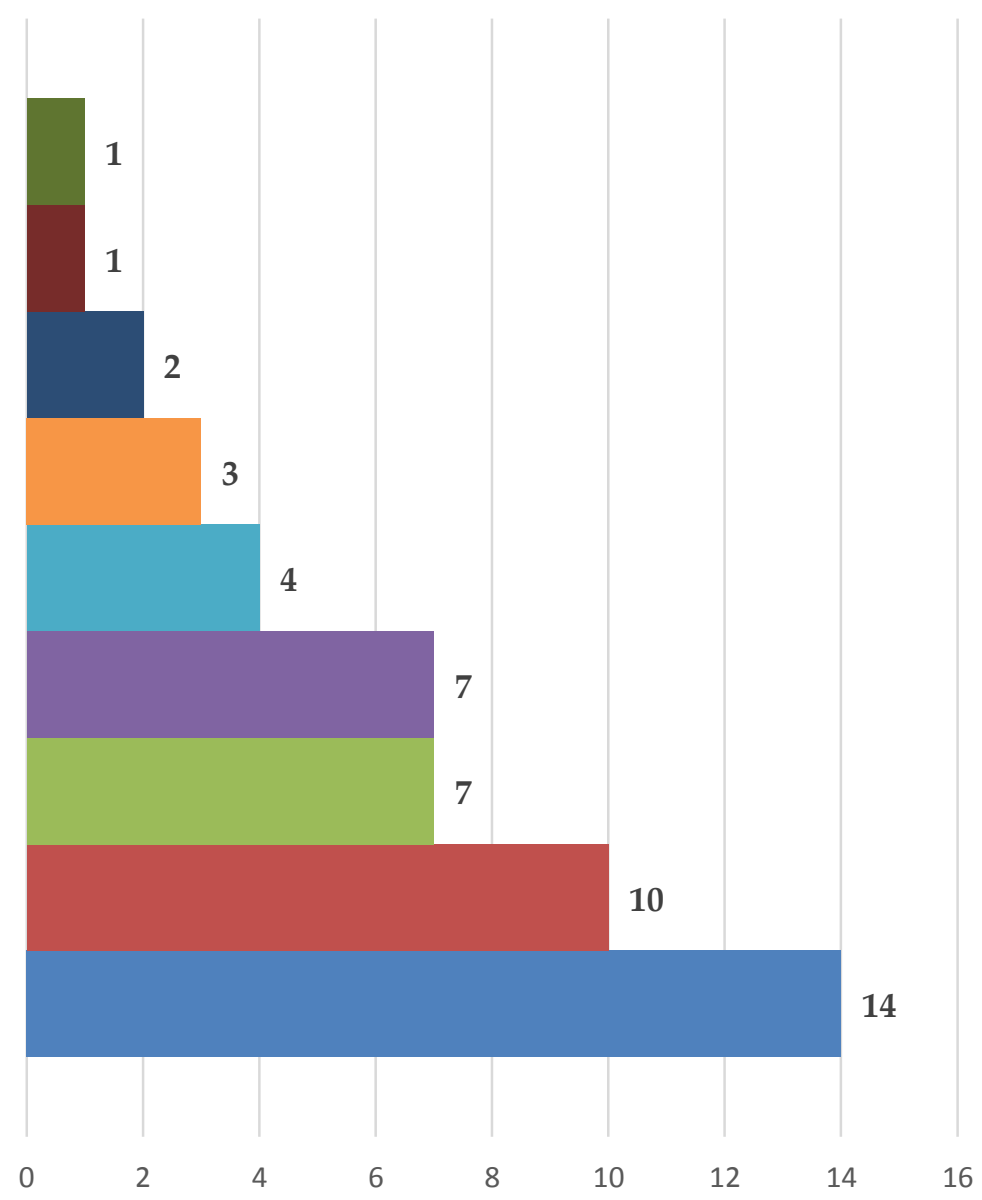

Figure 11. Frequency of disability types in articles

\section{Discussion and Conclusion}

This study aimed to provide an overview and analysis of the research trends on the use of serious games to assist people with disabilities. Bibliometric analysis results showed that serious game(s) is the most commonly used author keyword. In addition, games, digital games, educational games, and video games, together, are the second most used set of 
author keywords. It can be inferred from this finding that the term "serious game" has been used in the majority of articles, especially in recent years (Bang et al., 2019; Faria et al., 2019; García-Redondo et al., 2019; Jaramillo-Alcázar et al., 2020; Lievense et al., 2019; Ronimus et al., 2020; Tang et al., 2019). Based on the bibliometric results, disability and rehabilitation are also among the most used author keywords. The high use of "rehabilitation" as a keyword can be linked to the many articles published in the rehabilitation domain (Afyouni et al., 2017; Bonnechere et al., 2014; Hossain et al., 2016; Hossain et al., 2018; Martín-Ruiz et al., 2016; Ocampo \& Tavakoli, 2019; Rico-Olarte et al., 2017; van der Kuil et al., 2018). Based on the citation and co-citation analyses, Lyytinen, Ronimus, Gee, and Prensky were the most cited authors. All of these authors have many publications related to disability or serious or digital gaming. According to the bibliometric results, the USA was the most cited country. On the other hand, citing scores of England, Netherlands and Spain have been increased in recent years. This can be linked to the increasing number of serious game studies in the field of disability.

Based on the content analysis results, the most dominant fields in the study of serious games and disability were education, rehabilitation, medicine and health, psychology, and engineering. Similarly, in a systematic literature review of serious game evaluation, Calderón and Ruiz (2015) found that more than half of the serious games were included in the educational domain-related assessment studies. Based on their results, health and wellness were the second major domain of the studies examined. Additionally, Tsikinas and Xinogalos (2019) stated that the majority of studies involving serious games for people with intellectual disability and people with autism spectrum disorder were published in the domains of psychology, social sciences, computer science, and medicine. So, we can say that the study of serious games and disability mostly occur in social sciences, including education, and medicine, including rehabilitation.

Based on the findings of this study, the majority of the articles used quantitative methods. The literature shows that in recent years there has been an increasing number of quantitative studies focusing on the effects of serious games for people with different disabilities (Bang et al., 2019; van der Kuil et al., 2018). The findings also indicated that descriptive research methods as a non-experimental design and quasi- and true experimental 
research methods as experimental design were commonly used in quantitative design. These findings are supported by a review of research on the use of serious games in science education which found that quantitative research design is the most commonly used research approach in that field (Cheng et al., 2015). Besides education, Tsikinas and Xinogalos (2019) asserted that most of the published studies used a pretesting-posttesting strategy to investigate the effects of serious games to assist people with disabilities. Similarly, Lämsä, Hämäläinen, Aro, Koskimaa, and Äyrämö (2018) concluded, based on the systematic review of educational game design for people with learning disabilities, that most of the articles included pretests and posttests in research designs. It can be understood from these findings that both experimental and non-experimental methods in quantitative design were used in studies related to serious games and disability.

According to the findings of this study, questionnaires were the most commonly used data tool in published studies of serious games and disability over the last six years. Additionally, many research studies also used achievement/performance tests and game sessions/interactions for collecting data. That is, these research studies either examined players' interactions with games or players' actions during game sessions were used as data collection tools. While questionnaires and interviews were the most used techniques to assess serious games (Calderón \& Ruiz, 2015), this study indicates that game sessions/interactions were also used as a data collection tool in articles published over the last seven years. Adapting game sessions as data collection tools can be related to the studies implementing game analytics (Afyouni et al., 2017; Cano et al., 2018; Cano et al., 2019; Rahman, 2017).

With respect to the frequency of sampling groups, the majority of the articles included adults in the research. Similarly, the literature shows that adults mainly were included in serious game studies for people with intellectual disabilities (Tsikinas \& Xinogalos, 2019). Considering the sample sizes in published articles, a limited number of sample sizes were most commonly selected such as 1-10, 11-30 and 31-100. The finding of using small groups as sample sizes was supported in several studies in the literature (Calderón \& Ruiz, 2015; Cinquin, Guitton, \& Sauzéon, 2019; Lämsä et al., 2018; Tsikinas \& Xinogalos, 2019). With regard to the distribution of data analysis techniques, descriptive 
analysis methods were implemented more than inferential and qualitative methods. Inferential analysis methods were used more than qualitative analysis methods. These findings can be linked to the predominance of quantitative research design in articles published over the last seven years.

With regard to the use of gaming platforms in studies of serious games and disability, most of the articles included computer games. This finding has been repeated by many studies. For example, Tsikinas, Xinogalos, and Satratzemi (2016) mentioned the main role of PCs in serious games. In addition, PCs have gotten more recognition than mobile devices in serious game studies (Cheng \& Lai, 2020). Other studies also found that computer games are most commonly selected as the gaming platform for serious game studies (Calderón \& Ruiz, 2015; Cheng et al., 2015; Tsikinas \& Xinogalos, 2019). According to the content analysis findings, mobile games and motion-sensitive games were also used as gaming platforms in many studies. It can be inferred from this finding that researchers show an interest in using mobile devices and Kinect-like platforms to study serious games for people with disabilities. However, the question remains whether the number of studies using mobile games is adequate. Xie, Basham, Marino, and Rice (2018) expressed that more academic or research studies are needed to design and implement mobile devices for supporting the learning activities of disabled people. Another important finding related to the use of gaming platforms concerns the number of virtual and augmented reality games. This study's findings suggest that researchers have studied VR and AR serious games and disability at about the same rate as mobile and motion-sensitive gaming platforms. It can be stated based on this finding that the popularity of using VR and AR games in this field has increased over the last seven years. Bibliometric analysis findings also support this assertion because "virtual reality" was among the most cited keywords and especially in recent articles. Similarly, Cheng and Lai (2020) conducted a review of technology-supported special education studies and found that the use of VR gradually increased between 2013 and 2017. In addition, Valencia, Rusu, Quiñones, and Jamet (2019) carried out a systematic literature review for understanding the impact of technology on people with autism spectrum disorder. Based on the review, they found that the current research focus is on the integration of new technologies, such as VR and AR, for supporting disabled children. 
The last finding of this study concerns the number of different disability types studied in articles published over the last seven years. Based on the findings, intellectual disability was the most common disability type (Amado et al., 2016; Cano et al., 2018; Cano et al., 2019; Koh, 2020; Lopez-Basterretxea et al., 2014; Montenegro \& Greenhill, 2015; Terras et al., 2018; Tsikinas \& Xinogalos, 2019). Similarly, in the bibliometric analysis, intellectual disability appears on the networking map showing the most used keywords. This is probably because many of the reviewed articles were from the field of education. Since education tends to focus on cognitive issues, the number of studies focusing on intellectual disability and cognitive disability will be higher in this field compared to other disability types. Other research, especially from the field of education, supports this finding. Lämsä et al. (2018), based on a review study, indicated that the majority of educational games were used to help children with cognitive disabilities. Cheng and Lai (2020) also reported that most of the studies they reviewed were about disabled students' cognitive issues, including computer-assisted tools in special education.

\section{Recommendations}

The main objective of this content analysis study was to reveal research trends on the use of serious games to assist people with disabilities. Based on the findings, some suggestions can be presented. First, fields such as education, medicine and health, and rehabilitation, as well as other major fields, should be integrated into studies concerning the use of serious games to assist people with disabilities. Second, more qualitative research should be conducted to present detailed analyses on the use of serious games in the field of disability. Third, besides questionnaires and achievement/performance tests, the use of game sessions/interactions should be increased to collect more data about disabled people's actions during serious game play. Fourth, serious game studies of disability have mostly been conducted with adults with disabilities. However, there is a need for more detailed research on the use of serious games to assist preschool children and primary or secondary school students with disabilities. Fifth, computer games are the main gaming platform for serious games for people with disabilities. With the advancement of technology, more research should be conducted to understand the use and design of serious games for other platforms, such as VR and AR. Last, intellectual and developmental disabilities are the most prominent 
disability types in the literature over the last seven years. Integrating different types of disabilities such as visual and hearing impairments would be a useful contribution to the field of serious game studies.

Acknowledgement

The data used in this study does not require the approval of Institutional Ethical Review Board.

Authorship Contribution Statement

Nuri KARA: Conceptualization, design of the work, , literature search, data collection, data analysis, , data interpretation, writing - review and editing.

\section{References}

Afyouni, I., Rehman, F. U., Qamar, A. M., Ghani, S., Hussain, S. O., Sadiq, B., ... \& Basalamah, S. (2017). A therapy-driven gamification framework for hand rehabilitation. User Modeling and User-Adapted Interaction, 27(2), 215-265. https://doi.org/10.1007/s11257-017-9191-4

Amado, I., Brénugat-Herné, L., Orriols, E., Desombre, C., Dos Santos, M., Prost, Z., ... \& Piolino, P. (2016). A serious game to improve cognitive functions in schizophrenia: a pilot study. Frontiers in Psychiatry, 7, 64. https://doi.org/10.3389/fpsyt.2016.00064

Arici, F., Yildirim, P., Caliklar, S., \& Yilmaz, R. M. (2019). Research trends in the use of augmented reality in science education: Content and bibliometric mapping $\begin{array}{lllll}\text { analysis. } & \text { Computers } & \text { E } & \end{array}$ https://doi.org/10.1016/j.compedu.2019.103647

Bang, C., Nam, Y., Ko, E. J., Lee, W., Kim, B., Choi, Y., \& Park, Y. R. (2019) A serious gamederived index for detecting children with heterogeneous developmental disabilities: Randomized controlled trial. JMIR Serious Games, 7(4). https://doi.org/10.2196/14924

Bonnechere, B., Jansen, B., Omelina, L., Degelaen, M., Wermenbol, V., Rooze, M., \& Jan, S. V. S. (2014). Can serious games be incorporated with conventional treatment of children with cerebral palsy? A review. Research in Developmental Disabilities, 35(8), 1899-1913. https://doi.org/10.1016/j.ridd.2014.04.016

Boyle, E. A., Hainey, T., Connolly, T. M., Gray, G., Earp, J., Ott, M., ... \& Pereira, J. (2016). An update to the systematic literature review of empirical evidence of the impacts and outcomes of computer games and serious games. Computers $\mathcal{E}$ Education, 94, 178192. https://doi.org/10.1016/j.compedu.2015.11.003

Calderón, A., \& Ruiz, M. (2015). A systematic literature review on serious games evaluation: An application to software project management. Computers \& Education, 87, 396422. https://doi.org/10.1016/j.compedu.2015.07.011 
Cano, A. R., Fernández-Manjón, B., \& García-Tejedor, Á. J. (2018). Using game learning analytics for validating the design of a learning game for adults with intellectual disabilities. British Journal of Educational Technology,49(4), 659-672. https://doi.org/10.1111/bjet.12632

Cano, A. R., García-Tejedor, Á. J., Alonso-Fernández, C., \& Fernández-Manjón, B. (2019). Game analytics evidence-based evaluation of a learning game for intellectual disabled users. IEEE Access, 7, 123820-123829.

Cheng, M. T., Chen, J. H., Chu, S. J., \& Chen, S. Y. (2015). The use of serious games in science education: A review of selected empirical research from 2002 to 2013. Journal of Computers in Education, 2(3), 353-375. https://doi.org/10.1007/s40692-015-0039-9

Cheng, S. C., \& Lai, C. L. (2020). Facilitating learning for students with special needs: A review of technology-supported special education studies. Journal of Computers in Education, 7, 131-153. https://doi.org/10.1007/s40692-019-00150-8

Chow, C. Y., Riantiningtyas, R. R., Kanstrup, M. B., Papavasileiou, M., Liem, G. D., \& Olsen, A. (2020). Can games change children's eating behaviour? A review of gamification and serious games. Food Quality and Preference, 80, 103823. https://doi.org/10.1016/j.foodqual.2019.103823

Cinquin, P. A., Guitton, P., \& Sauzéon, H. (2019). Online e-learning and cognitive disabilities: A systematic review. Computers $\mathcal{E}$ Education, 130, 152-167. https://doi.org/10.1016/j.compedu.2018.12.004

Connolly, T. C., Boyle, E. A., Hainey, T., McArthur, E., \& Boyle, J. M. (2012). A systematic literature review of empirical evidence on computer games and serious games. Computers E Education, 59, 661-686. https://doi.org/10.1016/j.compedu.2012.03.004

Durkin, K., Boyle, J., Hunter, S., \& Conti-Ramsden, G. (2013). Video games for children and adolescents with special educational needs. Zeitschrift Für Psychologie, 221(2),79-89. https://doi.org/10.1027/2151-2604/a000138

Faria, B. M., Ribeiro, J. D., Moreira, A. P., \& Reis, L. P. (2019). Boccia game simulator: Serious game adapted for people with disabilities. Expert Systems, 36(3). https://doi.org/10.1111/exsy.12299

García-Redondo, P., García, T., Areces, D., Núñez, J. C., \& Rodríguez, C. (2019). Serious games and their effect improving attention in students with learning disabilities. International Journal of Environmental Research and Public Health, 16(14). https://doi.org/10.3390/ijerph16142480

Goktas, Y., Kucuk, S., Aydemir, M., Telli, E., Arpacik, O., Yildirim, G., \& Reisoglu, I. (2012). Educational technology research trends in Turkey: A content analysis of the 20002009 decade. Educational Sciences: Theory and Practice, 12(1), 177-199.

Hossain, M. S., Hardy, S., Alamri, A., Alelaiwi, A., Hardy, V., \& Wilhelm, C. (2016). ARbased serious game framework for post-stroke rehabilitation. Multimedia Systems, 22(6), 659-674. https://doi.org/10.1007/s00530-015-0481-6

Hossain, M. S., Hoda, M., Muhammad, G., Almogren, A., \& Alamri, A. (2018). Cloudsupported framework for patients in post-stroke disability rehabilitation. Telematics and Informatics, 35(4), 826-836. https://doi.org/10.1016/j.tele.2017.12.001 
Jaramillo-Alcázar, A., Cortez-Silva, P., Galarza-Castillo, M., \& Luján-Mora, S. (2020). A method to develop accessible online serious games for people with disabilities: A case study. Sustainability, 12(22), 9584. https://doi.org/10.3390/su12229584

Koh, C. (2020). A qualitative meta-analysis on the use of serious games to support learners with intellectual and developmental disabilities: What we know, what we need to know and what we can do. International Journal of Disability, Development and Education, https://doi.org/10.1080/1034912X.2020.1746245

Lämsä, J., Hämäläinen, R., Aro, M., Koskimaa, R., \& Äyrämö, S. M. (2018). Games for enhancing basic reading and maths skills: A systematic review of educational game design in supporting learning by people with learning disabilities. British Journal of Educational Technology, 49(4), 596-607. https://doi.org/10.1111/bjet.12639

Lievense, P., Vacaru, V. S., Liber, J., Bonnet, M., \& Sterkenburg, P. S. (2019). “Stop bullying now!" Investigating the effectiveness of a serious game for teachers in promoting autonomy-supporting strategies for disabled adults: A randomized controlled trial. Disability and Health Journal, 12(2), 310-317. https://doi.org/10.1016/j.dhjo.2018.11.013

Lopez-Basterretxea, A., Mendez-Zorrilla, A., \& Garcia-Zapirain, B. (2014). A telemonitoring tool based on serious games addressing money management skills for people with intellectual disability. International Journal of Environmental Research and Public Health, 11(3), 2361-2380. https://doi.org/10.3390/ijerph110302361

Martín-Ruiz, M. L., Máximo-Bocanegra, N., \& Luna-Oliva, L. (2016). A virtual environment to improve the detection of oral-facial malfunction in children with cerebral palsy. Sensors, 16(4), 444. https://doi.org/10.3390/s16040444

Michael, D., \& Chen, S. (2006). Serious games: Games that educate, train, and inform. Boston, MA: Thomson.

Montenegro, M., \& Greenhill, B. (2015). Evaluating "freda challenge": A coproduced human rights board game in services for people with intellectual disabilities. Journal of Applied Research in Intellectual Disabilities, 28(3), 223-237. https://doi.org/10.1111/jar.12124

Ocampo, R., \& Tavakoli, M. (2019). Improving user performance in haptics-based rehabilitation exercises by colocation of user's visual and motor axes via a threedimensional augmented-reality display. IEEE Robotics and Automation Letters, 4(2), 438-444. https://doi.org/10.1109/LRA.2019.2891283

Proença, J. P., Quaresma, C., \& Vieira, P. (2018). Serious games for upper limb rehabilitation: a systematic review. Disability and Rehabilitation: Assistive Technology, 13(1), 95-100. https://doi.org/10.1080/17483107.2017.1290702

Rahman, M. A. (2017). Web-based multimedia hand-therapy framework for measuring forward and inverse kinematic data. Multimedia Tools and Applications, 76(6), 82278255. https://doi.org/10.1007/s11042-016-3447-6

Rico-Olarte, C., López, D. M., Narváez, S., Farinango, C. D., \& Pharow, P. S. (2017). HapHopPhysio: A computer game to support cognitive therapies in children. Psychology Research and Behavior Management, 10, 209-217. https://doi.org/10.2147/PRBM.S130998 
Ronimus, M., Eklund, K., Westerholm, J., Ketonen, R., \& Lyytinen, H. (2020). A mobile game as a support tool for children with severe difficulties in reading and spelling. Journal of Computer Assisted Learning, 36(6), 1011-1025. https://doi.org/10.1111/jcal.12456

Susi, T., Johannesson, M., \& Backlund, P. (2007). Serious games, an overview. Technical report HIS-IKI-TR-07-001. University of Skvde.

Tang, J. S., Chen, N. T., Falkmer, M., Bölte, S., \& Girdler, S. (2019). A systematic review and meta-analysis of social emotional computer based interventions for autistic individuals using the serious game framework. Research in Autism Spectrum Disorders, 66, 101412. https://doi.org/10.1016/j.rasd.2019.101412

Terras, M. M., Boyle, E. A., Ramsay, J., \& Jarrett, D. (2018). The opportunities and challenges of serious games for people with an intellectual disability. British Journal of Educational Technology, 49(4), 690-700. https://doi.org/10.1111/bjet.12638

Tsikinas, S., \& Xinogalos, S. (2019). Studying the effects of computer serious games on people with intellectual disabilities or autism spectrum disorder: A systematic literature review. Journal of Computer Assisted Learning, 35(1), 61-73. https://doi.org/10.1111/jcal.12311

Tsikinas, S., Xinogalos, S., \& Satratzemi, M. (2016). Review on serious games for people with intellectual disabilities and autism. 10th European Conference on Games Based Learning, 696-703. Academic Conferences International Limited.

Valencia, K., Rusu, C., Quiñones, D., \& Jamet, E. (2019). The impact of technology on people with autism spectrum disorder: A systematic literature review. Sensors, 19(20). https://doi.org/10.3390/s19204485

Van der Kuil, M. N., Visser-Meily, J., Evers, A. W., \& Van der Ham, I. J. (2018). A usability study of a serious game in cognitive rehabilitation: A compensatory navigation training in acquired brain injury patients. Frontiers in Psychology, 9, 846. https://doi.org/10.3389/fpsyg.2018.00846

World Health Organization (Geneva). (2011). World report on disability. World Health Organization.

Xie, J., Basham, J. D., Marino, M. T., \& Rice, M. F. (2018). Reviewing research on mobile learning in k-12 educational settings: Implications for students with disabilities. Journal of Special Education Technology, 33(1), 27-39. https://doi.org/10.1177/0162643417732292

Copyright $($ JCER

JCER's Publication Ethics and Publication Malpractice Statement are based, in large part, on the guidelines and standards developed by the Committee on Publication Ethics (COPE). This article is available under Creative Commons CC-BY 4.0 license (https://creativecommons.org/licenses/by/4.0/) 